The physics and technology basis entering European system code studies for DEMO

This content has been downloaded from IOPscience. Please scroll down to see the full text.

2017 Nucl. Fusion 57016011

(http://iopscience.iop.org/0029-5515/57/1/016011)

View the table of contents for this issue, or go to the journal homepage for more

Download details:

IP Address: 157.193.64.157

This content was downloaded on 11/04/2017 at 15:44

Please note that terms and conditions apply.

You may also be interested in:

Advances in the physics basis for the European DEMO design

R. Wenninger, F. Arbeiter, J. Aubert et al.

Modelling of pulsed and steady-state DEMO scenarios

G. Giruzzi, J.F. Artaud, M. Baruzzo et al.

DEMO divertor limitations during and in between ELMs

R.P. Wenninger, M. Bernert, T. Eich et al.

Fusion nuclear science facilities and pilot plants based on the spherical tokamak

J.E. Menard, T. Brown, L. El-Guebaly et al.

Overview of physics basis for ITER

V Mukhovatov, M Shimada, A N Chudnovskiy et al.

Prospects for pilot plants based on the tokamak, spherical tokamak and stellarator

J.E. Menard, L. Bromberg, T. Brown et al.

Chapter 3: MHD stability, operational limits and disruptions

T.C. Hender, J.C Wesley, J. Bialek et al.

The requirements of a next step large steady state tokamak

G. Janeschitz, P. Barabaschi, G. Federici et al. 


\title{
The physics and technology basis entering European system code studies for DEMO
}

\author{
R. Wenninger ${ }^{1,2}$, R. Kembleton ${ }^{3}$, C. Bachmann ${ }^{1}$, W. Biel ${ }^{4}$, T. Bolzonella ${ }^{7}$, \\ S. Ciattaglia ${ }^{1}$, F. Cismondi ${ }^{1}$, M. Coleman ${ }^{1}$, A.J.H. Donnéé ${ }^{1,5}$, T. Eich $^{2}$, \\ E. Fable ${ }^{2}$, G. Federici ${ }^{1}$, T. Franke ${ }^{1}$, H. Lux ${ }^{3}$, F. Maviglia ${ }^{1}$, B. Meszaros ${ }^{1}$, \\ T. Pütterich ${ }^{2}$, S. Saarelma ${ }^{3}$, A. Snickers ${ }^{2}$, F. Villone ${ }^{6}$, P. Vincenzi ${ }^{7}$, D. Wolff ${ }^{3}$ \\ and H. Zohm ${ }^{2}$ \\ 1 EUROfusion Programme Management Unit, Garching, Germany \\ 2 Max-Planck-Institut für Plasmaphysik, Garching, Germany \\ ${ }^{3}$ Culham Centre for Fusion Energy, Culham Science Centre, Abingdon, UK \\ ${ }^{4}$ Institute of Energy- and Climate Research, Forschungszentrum Jülich GmbH, Jülich, Germany \\ ${ }^{5}$ FOM-Institute DIFFER, Dutch Institute for Fundamental Energy Research, 5600 HH Eindhoven, \\ The Netherlands \\ ${ }^{6}$ Università di Cassino, Cassino, Italy \\ ${ }^{7}$ Consorzio RFX, Padova, Italy \\ E-mail: ronald.wenninger@euro-fusion.org
}

Received 16 June 2016, revised 5 August 2016

Accepted for publication 29 August 2016

Published 11 October 2016

\begin{abstract}
A large scale program to develop a conceptual design for a demonstration fusion power plant (DEMO) has been initiated in Europe. Central elements are the baseline design points, which are developed by system codes. The assessment of the credibility of these design points is often hampered by missing information. The main physics and technology content of the central European system codes have been published (Kovari et al 2014 Fusion Eng. Des. 89 3054-69, 2016 Fusion Eng. Des. 104 9-20, Reux et al 2015 Nucl. Fusion 55 073011). In addition, this publication discusses key input parameters for the pulsed and conservative design option EU DEMO1 2015 and provides justifications for the parameter choices. In this context several DEMO physics gaps are identified, which need to be addressed in the future to reduce the uncertainty in predicting the performance of the device.

Also the sensitivities of net electric power and pulse duration to variations of the input parameters are investigated. The most extreme sensitivity is found for the elongation $\left(\Delta \kappa_{95}=10 \%\right.$ corresponds to $\left.\Delta P_{\mathrm{el}, \mathrm{net}}=125 \%\right)$.
\end{abstract}

Keywords: DEMO, system code, physics basis

(Some figures may appear in colour only in the online journal)

\section{Introduction}

The European fusion roadmap [4] identifies the development of a conceptual design for a demonstration fusion power plant (DEMO) as one of the main priorities for the coming decades. Such a conceptual design has to be based on an optimized set of key parameters. System codes representing all aspects of the plant that are important for the feasibility or the performance of the design are the central tool to develop such a parameter set. To allow for optimization and multi-dimensional scans they are designed to develop single consistent design points (non-optimized) within less than a second. In the framework of the European DEMO design point development two system codes, which widely fulfil these criteria, are used: PROCESS $[1,2]$ and SYCOMORE [3]. The former system code has been used for all calculations in this publication.

Results of system code studies are frequently benchmarked with results of investigation methods that focus on a single area-typically with a much higher level of detail. If there is a significant discrepancy, parameters or even complete modules 
in the system have to be modified. This leads to a continuous improvement of the system code. For instance, as a result of a comparison of system code (PROCESS) and transport code outputs, a recently instigated upgrade of the core transport model in system codes to a fully consistent 1D model is currently ongoing.

System codes mainly describe the flat-top phase of the discharge. Dynamic aspects are only featured if they impact on the overall design of the machine.

While the relations used in the system code calculations have been published [1,2], the physics and technology assumptions that are entering recent system code runs for DEMO are not. Therefore, after a short introduction of the recent European design options in section 2, section 3 briefly describes functional dependences inside the system code PROCESS (table 1) and concentrates on the motivation for the selection of physical and technological input parameters, where the emphasis is on the physical side. Section 4 is dedicated to the sensitivity of the system code output (performance parameters) to variations of the input parameters.

\section{DEMO design options}

A group of experts representing various DEMO stakeholders has started to develop a set of high-level requirements for DEMO. The identified areas of requirements are safety and environmental sustainability, plant performance and economic viability. In terms of performance it has been recommended that the DEMO plant shall produce a minimum of $300 \mathrm{MW}$ of electricity. From the view point of the stakeholders, pulsed operation of DEMO is acceptable. As the high-level requirements are not formulated in a more restrictive way, there is some freedom in the definition of DEMO.

In the European design point development studies two main DEMO design options are developed [5]:

- The near-term DEMO (DEMO1): this is a DEMO concept that is compatible with a fast track to fusion energy (e.g. construction possibly starting 20 years from now). It is based on the expected performance of ITER $(Q=10)$ with conservative improvements in science and technology. It is a relatively large device with modest power density operating pulsed (i.e. finite inductively driven current) with relatively long discharges. The design of the balance of plant uses mature and reliable technology.

- The advanced DEMO (DEMO2): this is based on more optimistic physics assumptions, which are at the upper limit of what may be achieved in ITER phase 2. DEMO2 has a higher power density and an advanced plasma scenario (e.g. hybrid plasma). It is clear that this can only be realised on a longer timescale, assuming that the required significant advances in the physics basis can be demonstrated using ITER and the limited number of satellite fusion devices available in the next 10-20 years. Also some engineering assumptions (e.g. heating and current drive system parameters) are more optimistic when compared to DEMO1.
Both DEMO1 and DEMO2 are assumed to operate with a plasma in H-mode conditions. It is clear that this implies significant challenges when compared to L-mode (e.g. ELM mitigation). However the benefits in terms of device size [6] and consequently cost of electricity are of an extent that the recent strategy is to face these challenges. Both options operate at finite values of the fusion gain $Q$, hence under non-ignited conditions. In addition to this, a lower single null plasma configuration is assumed in this work.

As the ongoing EU concept design analysis is mainly based on DEMO1, we use the design EU DEMO1 2015 [7] as the main reference for this publication.

\section{Key parameters}

System codes typically involve an extensive number of parameters (e.g. PROCESS $>1000$ ). Correspondingly, the optimization of a design option within the physical laws and engineering constraints is a multidimensional problem, which involves numerous non-linearities. For this type of non-linear constrained optimisation problem there is no truly global method available and in the case of PROCESS a combination of a local algorithm with expert interpretation of the results is used to assure the solution corresponds to a global optimum. Hence it is advantageous to understand the principal dependences between the crucial parameters.

In addition to the distinction into input and output parameters we distinguish four types of parameters:

- Requirement parameters (RQ): these are linked to toplevel requirements. Requirement parameters are related to the overall performance of the plant as a whole.

- Design parameters (DP): these describe the fundamental design of the plant including the effect of key actuators.

- Physics parameters (PP): these detail the plasma scenario.

- Technical parameters (TP): these specify properties of technical systems having significant impact on the performance of the plant as a whole.

Certainly the boundary between design parameters and physics/technical parameters is not in every case precisely defined and it has been aimed to make reasonable choices.

Table 1 lists the most important system code parameters including values for the designs EU DEMO1 2015 and EU DEMO2 2015. The parameters describe the flat-top phase of the discharge. For all design parameters, physics parameters and technical parameters determined by relations inside the system code (i.e. output parameters), these dependences are briefly indicated. As the dependences in system codes are often circular, there are multiple ways to display them, from which one option has been chosen. We note that more detailed descriptions of the system code PROCESS relations have been published $[1,2]$. For all other parameters (input), in the remainder of this section the choice for EU DEMO1 2015 is justified-mostly by results of other investigations. Also for several of the calculated parameters we provide some comparison to other investigations. 
Table 1. Most important system code parameters including units and values for the designs EU DEMO1 2015 and EU DEMO2 2015 : in the last column, for EU DEMO1 2015 some indication on the calculation of this parameter inside the system code is given.

\begin{tabular}{|c|c|c|c|c|c|c|}
\hline Parameter & Short form & Type & Unit & DEMO1 & DEMO2 & $\begin{array}{l}\text { Determined for DEMO1 in } \\
\text { system code by }\end{array}$ \\
\hline Net electric power & $P_{\text {el, net }}$ & RQ & MW & 500 & 953 & Design target: $P_{\mathrm{el}, \text { gross }}, P_{\text {rec,tot }}$ \\
\hline Pulse duration & $\tau_{\text {pulse }}$ & RQ & $\mathrm{h}$ & 2 & inf & Design target: inductive flux, loop voltage \\
\hline Major radius & $R$ & DP & $\mathrm{m}$ & 9.1 & 7.5 & Figure of merit (minimised) \\
\hline Aspect ratio & $A$ & DP & 1 & 3.1 & 2.6 & \\
\hline $\begin{array}{l}\text { Elongation at } 95 \% \text { flux } \\
\text { surface }\end{array}$ & $\kappa_{95}$ & DP & 1 & 1.59 & 1.8 & \\
\hline $\begin{array}{l}\text { Triangularity at } 95 \% \text { flux } \\
\text { surface }\end{array}$ & $\delta_{95}$ & DP & & 0.33 & 0.33 & \\
\hline $\begin{array}{l}\text { Toroidal magnetic field at } \\
\text { plasma centre }\end{array}$ & $B_{T, 0}$ & DP & $\mathrm{T}$ & 5.7 & 5.6 & Radial build, $B_{\mathrm{T}, \text { max,cond }}$ \\
\hline Number of TF coils & $n_{\mathrm{TF}}$ & DP & 1 & 18 & 18 & \\
\hline Edge safety factor & $q_{95}$ & DP & 1 & 3.2 & 4.4 & $B_{T, 0}, I_{P}$ \\
\hline Plasma current & $I_{\mathrm{P}}$ & DP & MA & 19.6 & 21.6 & $\begin{array}{l}q_{95}, B_{T, 0}, \text { geometry parameters, } \\
\text { confinement }\end{array}$ \\
\hline $\begin{array}{l}\text { Pedestal top electron } \\
\text { density }\end{array}$ & $n_{\text {ped }}$ & $\mathrm{PP}$ & $10^{20} \mathrm{~m}^{-3}$ & 0.62 & 0.63 & \\
\hline Central electron density & $n_{0}$ & $\mathrm{PP}$ & $10^{20} \mathrm{~m}^{-3}$ & 1.01 & 1.22 & $\begin{array}{l}n_{\text {ped }} \text {, core transport, limit on Greenwald } \\
\text { density fraction }\end{array}$ \\
\hline $\begin{array}{l}\text { Average Greenwald } \\
\text { density fraction }\end{array}$ & $\left\langle n_{\text {line }}\right\rangle / n_{\mathrm{GW}}$ & PP & 1 & 1.2 & 1.2 & \\
\hline $\begin{array}{l}\text { Pedestal top electron } \\
\text { temperature }\end{array}$ & $T_{\text {ped }}$ & PP & $\mathrm{keV}$ & 5.5 & 5.5 & \\
\hline $\begin{array}{l}\text { Central electron } \\
\text { temperature }\end{array}$ & $T_{0}$ & PP & $\mathrm{keV}$ & 27.4 & 34.6 & $T_{\text {ped }} \&$ core transport \\
\hline Temperature peaking & $T_{0} /\left\langle T_{\mathrm{e}}\right\rangle$ & $\mathrm{PP}$ & 1 & 2.1 & 1.9 & \\
\hline Total normalised plasma $\beta$ & $\beta_{\mathrm{N}, \mathrm{tot}}$ & PP & $\%$ & 2.6 & 3.8 & $\begin{array}{l}\text { Profiles of thermal and fast particle } \\
\text { pressure, } B_{T, 0}\end{array}$ \\
\hline Total poloidal plasma $\beta$ & $\beta_{\text {pol,tot }}$ & PP & 1 & 1.1 & 1.7 & $\beta_{\text {tot }}, B_{\text {tot }}, B_{\mathrm{pol}}$ \\
\hline Seed impurity species & & $\mathrm{PP}$ & & $\mathrm{Xe}$ & $\mathrm{Xe}$ & \\
\hline $\begin{array}{l}\text { Seed impurity } \\
\text { concentration }\end{array}$ & $c_{\mathrm{imp}}$ & PP & 1 & $3.9 \times 10^{-4}$ & $1.0 \times 10^{-3}$ & Radiation / power exhaust $\& P_{\mathrm{LH}}$ \\
\hline Tungsten concentration & $c_{\mathrm{W}}$ & $\mathrm{PP}$ & 1 & $5.0 \times 10^{-5}$ & $1.0 \times 10^{-4}$ & \\
\hline Helium concentration & $c_{\mathrm{He}}$ & PP & 1 & $1.0 \times 10^{-1}$ & $1.0 \times 10^{-1}$ & \\
\hline Effective charge & $Z_{\text {eff }}$ & PP & 1 & 2.6 & 4.7 & $\left\langle n_{e}\right\rangle,\left\langle n_{f}\right\rangle, c_{\mathrm{He}}, c_{W}, c_{\mathrm{imp}}$ \\
\hline Fusion power & $P_{\text {fus }}$ & PP & MW & 2037 & 3255 & $\begin{array}{l}\text { Profiles of density and temperature, } \\
\text { DT-ratio }\end{array}$ \\
\hline $\begin{array}{l}\text { Bremsstrahlung radiation } \\
\text { power }\end{array}$ & $P_{\text {rad,brem }}$ & PP & MW & 88 & 210 & $\begin{array}{l}\text { Profiles of electron and impurity density } \\
\text { and temperature, Z_eff }\end{array}$ \\
\hline Line radiation power & $P_{\text {rad,line }}$ & PP & MW & 192 & 368 & $\begin{array}{l}\text { Profiles of electron and impurity density } \\
\text { and temperature, impurity concentrations }\end{array}$ \\
\hline $\begin{array}{l}\text { Synchrotron radiation } \\
\text { power }\end{array}$ & $P_{\text {rad,syn }}$ & PP & MW & 26 & 58 & $\begin{array}{l}\text { Profiles of electron and impurity density } \\
\text { and temperature, synchotron wall } \\
\text { reflection coefficient }\end{array}$ \\
\hline $\begin{array}{l}\text { Power crossing } \\
\text { separatrix }\end{array}$ & $P_{\text {sep }}$ & PP & MW & 154 & 150 & $P_{\alpha}, P_{\text {aux }}, P \_$rad, core, $P_{\text {rad,edge }}$ \\
\hline $\begin{array}{l}\text { Scaled LH threshold } \\
\text { power }\end{array}$ & $P_{\mathrm{LH}}$ & PP & MW & 133 & 128 & ITPA Scaling [8] \\
\hline$P_{\mathrm{sep}} / P_{\mathrm{LH}}$ & $f_{\mathrm{LH}}$ & PP & 1 & 1.2 & 1.2 & Manually checked \\
\hline $\begin{array}{l}\text { Confinement factor } \\
\text { (radiation corrected) }\end{array}$ & $H$ & PP & 1 & 1.1 & 1.4 & \\
\hline Energy confinement time & $\tau_{\mathrm{E}}$ & PP & $\mathrm{s}$ & 4.2 & 4 & $\tau_{\mathrm{E}, \mathrm{scal}}, \mathrm{H}$ \\
\hline Inductively driven current & $I_{\text {ind }}$ & PP & MA & 10.8 & 0 & $I_{P}, I_{\mathrm{BS}}, I_{\mathrm{CD}}$ \\
\hline Bootstrap current & $I_{\mathrm{BS}}$ & PP & MA & 6.9 & 13.2 & [9] \\
\hline $\begin{array}{l}\mathrm{H} \& \mathrm{CD} \text { power coupled to } \\
\text { the plasma }\end{array}$ & $P_{\text {aux }}$ & PP & MW & 50 & 133 & \\
\hline
\end{tabular}


Table 1. (Continued)

\begin{tabular}{|c|c|c|c|c|c|c|}
\hline Parameter & Short form & Type & Unit & DEMO1 & DEMO2 & $\begin{array}{l}\text { Determined for DEMO1 in } \\
\text { system code by }\end{array}$ \\
\hline Externally driven current & $I_{\mathrm{CD}}$ & $\mathrm{PP}$ & MA & 1.9 & 8.4 & $P_{\text {aux }}, \gamma_{\mathrm{CD}}$ \\
\hline Internal inductance & $l_{\mathrm{i}}$ & PP & 1 & 1.2 & 0.9 & $\begin{array}{l}\text { Current peaking (calculated from } q_{0} \text { and } \\
q_{95} \text { assuming a parabolic current profile) }\end{array}$ \\
\hline $\begin{array}{l}\text { Divertor challenge } \\
\text { quantifier }\end{array}$ & $P_{\mathrm{sep}} / R$ & PP & $\mathrm{MW} / \mathrm{m}$ & 17 & 20 & \\
\hline $\begin{array}{l}\text { H\&CD wall plug } \\
\text { efficiency }\end{array}$ & $\eta_{\mathrm{WP}}$ & $\mathrm{TP}$ & 1 & 0.4 & 0.5 & \\
\hline Current drive efficiency & $\gamma_{\mathrm{CD}}$ & $\mathrm{TP}$ & $\begin{array}{l}10^{20} \mathrm{~A} \\
\left(\mathrm{~W} \mathrm{~m}^{-2}\right)\end{array}$ & 0.27 & 0.41 & Plasma and CD system parameters \\
\hline Main coolant & & $\mathrm{TP}$ & - & $\mathrm{He}$ & $\mathrm{He}$ & \\
\hline $\begin{array}{l}\text { Thermo-dynamic } \\
\text { efficiency }\end{array}$ & $\eta_{\mathrm{TD}}$ & $\mathrm{TP}$ & 1 & 0.38 & 0.4 & \\
\hline Gross electric power & $P_{\mathrm{el}, \text { gross }}$ & $\mathrm{TP}$ & MW & 914 & 1660 & $P_{\text {fus }}, \eta_{\mathrm{TD}}$ \\
\hline Pumping power & $P_{\text {pump }}$ & $\mathrm{TP}$ & MW & 155 & 300 & \\
\hline Electric power for $\mathrm{HCD}$ & $P_{\mathrm{HCD} \text {,tot }}$ & $\mathrm{TP}$ & MW & 125 & 266 & $I_{\mathrm{CD}}, \eta_{\mathrm{WP}}, \gamma_{\mathrm{CD}}$ \\
\hline $\begin{array}{l}\text { Tritium processing } \\
\text { power }\end{array}$ & $P_{\text {Tritium }}$ & $\mathrm{TP}$ & MW & 15 & 15 & \\
\hline Cryogenic plant power & $P_{\text {cryo }}$ & $\mathrm{TP}$ & MW & 29 & 30 & $\begin{array}{l}\text { Cold mass of components, magnet } \\
\text { temperature, power deposited by neutrons }\end{array}$ \\
\hline Total recirculating power & $P_{\text {rec, tot }}$ & $\mathrm{TP}$ & MW & 413 & 706 & $\begin{array}{l}P_{\text {pump }}, P_{\mathrm{HCD}, \text { tot }}, P_{\text {Tritium }}, P_{\text {cryo }} \text { and other } \\
\text { electric power demands }\end{array}$ \\
\hline $\begin{array}{l}\text { Total recirculating power } \\
\text { fraction }\end{array}$ & $f_{\text {recirc }}$ & $\mathrm{TP}$ & 1 & 0.45 & 0.43 & $P_{\text {el,gross }}, P_{\text {rec, tot }}$ \\
\hline $\begin{array}{l}\text { Maximum field at the TF } \\
\text { conductor }\end{array}$ & $B_{\mathrm{T}, \max , \text { cond }}$ & $\mathrm{TP}$ & $\mathrm{T}$ & 12.3 & 15.6 & $\begin{array}{l}\text { TF dimensions and critical current density } \\
\text { in the conductor (function of magnetic } \\
\text { field, temperature and strain) }\end{array}$ \\
\hline $\mathrm{PF} / \mathrm{CS}$ coil-materials & & $\mathrm{TP}$ & - & $\mathrm{Nb}_{3} \mathrm{Sn} / \mathrm{NbTi}$ & $\mathrm{Nb}_{3} \mathrm{Sn} / \mathrm{NbTi}$ & \\
\hline $\begin{array}{l}\text { Inboard blanket and first } \\
\text { wall thickness }\end{array}$ & $t_{\mathrm{blkt}, \mathrm{ib}}$ & $\mathrm{TP}$ & $\mathrm{m}$ & 0.78 & 0.78 & \\
\hline $\begin{array}{l}\text { Outboard blanket and first } \\
\text { wall thickness }\end{array}$ & $t_{\mathrm{blkt}, \mathrm{ob}}$ & $\mathrm{TP}$ & $\mathrm{m}$ & 1.3 & 1.3 & \\
\hline $\begin{array}{l}\text { Average Neutron Wall } \\
\text { Load }\end{array}$ & $q_{\text {neut,wall,av }}$ & $\mathrm{TP}$ & $\mathrm{MW} / \mathrm{m}^{2}$ & 1.05 & 1.91 & $P_{\text {fus }}$, plasma surface area \\
\hline
\end{tabular}

\subsection{Requirement parameters}

The requirement parameters used in this study are net electric output power $P_{\mathrm{el}, \text { net }}$ and pulse duration $\tau_{\text {pulse }}($ table 1 ).

A further important performance parameter describing the economic efficiency of a power plant is the fraction of recirculated power $f_{\text {rec }}=P_{\text {rec,tot }} / P_{\text {el,gross. }}$ Despite the fact that $f_{\text {rec }}$ has the character of a requirement parameter, in this study it is treated as a technical parameter (output) in order to avoid excessively restricting the system to be optimized.

\subsection{Design parameters}

In the following a set of parameters describing the fundamental design of the plant is discussed.

3.2.1. Major radius. For the development of EUDEMO1 2015 the major radius $R$ was minimized. Certainly, the capital cost is the quantity that really should be minimized for DEMO. If this is done at fixed $P_{\mathrm{el} \text {,net }}$ and $\tau_{\text {pulse }}$ with the recent PROCESS cost model, the major radius is increased by $1.5 \%$.
Due to this small deviation it is reasonable to minimize $R$, as the performance of the cost model is non-critical in this case.

3.2.2. Aspect ratio. The aspect ratio $A=R / a$ is a central design parameter. There is freedom in the choice of $A$. However, $A$ in combination with other parameters determines the radial build of the device and has potential impact directly or indirectly on the following areas:

- vertical plasma stability

- disruption forces

- transport effects

- inter-pulse duration

- toroidal field ripple

- neutral beam current drive efficiency and design integration

- electron cyclotron current drive efficiency

- tritium breeding

- maintenance of in-vessel components

- overall availability

- cost. 
Investigations of the effect of the aspect ratios on each of these areas have been started based on configurations with $A=2.6$, $A=3.1$ and $A=3.6$. These have been based on system code runs, in which $P_{\text {el,net }}$ and $\tau_{\text {pulse }}$ have been fixed. The maximum variation of major radius between these three design points is $3 \%$.

Remote maintainability is a key requirement for any DEMO design concept [10]. The technical feasibility and speed of maintenance are indirectly related to $A$ and the number of toroidal field coils $n_{\mathrm{TF}}$. These two parameters are intrinsically linked to the size and number of blanket segments, and the size and number of vertical ports through which the blankets must be extracted. In an initial study several simplified tokamak design points were assessed in terms of technical feasibility and speed of remote maintenance operations scanning $A(2.6,3.1,3.6)$ and $n_{\mathrm{TF}}(16,18)$ [11]. A number of design parameters correlated with remote maintenance performance were considered. These parameters included:

- the number of in-vessel components requiring maintenance and the number of movements required to extract them (strongly related to the duration of maintenance activities)

- the volume and length of the blanket, as well as the relative stresses and torques at the RM lifting interfaces to the blanket (strongly related to the technical difficulty of remote maintenance)

Relative weightings for the impact of the parameters on both remote maintenance speed and technical feasibility have been introduced. The values of the parameters for each design point along with associated weightings were used to calculate values for two figures of merit relating to the remote maintainability speed and feasibility.

This study identified that the aspect ratio is the stronger performance driver in terms of remote maintenance. Overall, from a maintenance perspective (for both maintenance speed and technical feasibility), within the range of configurations considered, the results are clear: a larger aspect ratio machine with fewer TF coils is preferable. It is important to note that the feasibility of remote maintenance has not been fully proven for any of the configurations investigated.

Next to these advantages of higher aspect ratios, there are also significant advantages of lower aspect ratios. At almost constant $R$, increasing $A$ leads to increasing the ratio of the distance between plasma center and vessel to the minor radius, which leads to less vertical stability. It has been reported that the elongation $\kappa_{95}$, for which the stability margin $m_{\mathrm{s}}$ is equal to the proposed limit for single null configurations $m_{\mathrm{s}}=0.3$, is reduced for higher aspect ratios [12]. Consequently the maximum tolerable elongation, especially in the crucial phase at the start of the ramp-down (SRD), is reduced (table 2). In this phase also the required power for vertical stability control increases with aspect ratio [12].

The forces on the blanket during a disruption are increased by a factor of about 3 when increasing the aspect ratio from 2.6 to 3.6 (table 2). On one side the toroidal magnetic field increases and on the other side the currents induced in the blanket are also higher as the current quench time (assumed to scale with $a^{2}$ ) and the radial distance between magnetic axis and blanket center are reduced.
Table 2. Comparison of properties related to vertical stability, disruption loads and tritium breeding ratio for three aspect ratios.

\begin{tabular}{lrrr}
\hline$A$ & 2.6 & 3.1 & \multicolumn{1}{l}{3.6} \\
\hline$\kappa_{95}$ at $m_{\mathrm{s}}=0.3$ (SRD) & 1.65 & 1.71 & 1.56 \\
Fast disruption load on blanket (a.u.) & 0.51 & 1.00 & 1.44 \\
$\Delta \mathrm{TBR}$ & +0.04 & 0 & -0.02 \\
\hline
\end{tabular}

Also the tritium breeding ratio (TBR) is expected to be significantly reduced, when going from $A=2.6$ to $A=3.6$ (table 2). Assuming that the poloidal length, that is covered by the divertor and hence does not contribute to the tritium breeding, is constant, at lower minor radius (higher $A$ ) the remaining fraction available for tritium breeding is smaller than at higher minor radius.

The physics basis is by far best known for the ITER value $A=3.1$. Although not all facets have been conclusively investigated so far, a preliminary aspect ratio of 3.1 has been chosen for EU DEMO1 2015.

3.2.3. Plasma shape. The Elongation is the first moment of the plasma shape. The upper limit of $\kappa_{95}$ corresponds to a limit of the plasma vertical stability. There is a large range in the assumptions on the elongation in the international variety of DEMO parameter proposals ranging from conservative to extremely optimistic values.

Investigations of the passive and active stability properties of recent DEMO1 designs [12] have shown that the maximum elongation that is acceptable from a vertical stability point of view is $\kappa_{95}=1.71$ for the flat-top phase of the discharge and $\kappa_{95}=1.59$ for the start of the ramp-down. The difference is predominantly caused by the higher value of the internal inductance in the latter phase. It is an important question, which of the two values to use for the design of the device. On the one hand it might be possible to design the ramp-down in such a way that the vertical stability situation at the start of the ramp-down can be improved. On the other hand one has to assume that unplanned, not fully controlled H-L-transitions can happen at any time. After such an event the plasma would have reduced vertical stability qualities and consequently the disruption risk would increase until the plasma was transferred back to the original state. In line with these considerations and the conservative approach used for EU DEMO1 2015, $\kappa_{95}=1.59$ has been selected ${ }^{8}$.

The triangularity $\delta_{95}$ is the second moment of the plasma shape. Several relevant dependences on $\delta_{95}$ are known. An advantageous effect of increasing triangularity is a higher confinement-mainly due to higher pedestal top temperature at constant pedestal top density, observed in attached plasmas. Figure 2 shows that for EU DEMO1 2015 this effect saturates at an edge triangularity $\delta_{x}$ of about 0.6 , which corresponds to $\delta_{95} \approx 0.4$. Disadvantages are larger type I ELMs, larger disruption forces, a higher level of impurity accumulation and more difficulties to solve the first wall heat load problem at the top

${ }^{8}$ In PROCESS the elongation is calculated via $\kappa_{95}=(1.5+0.5 /(A-1)) / 1.12$ [2]. Due to the high sensitivity on this parameter for EU DEMO1 2015 the result from the vertical stability analysis $\kappa_{95}=1.59$ has been imposed, which corresponds to an increase of $\kappa_{95}$ by $2.4 \%$. 
a)

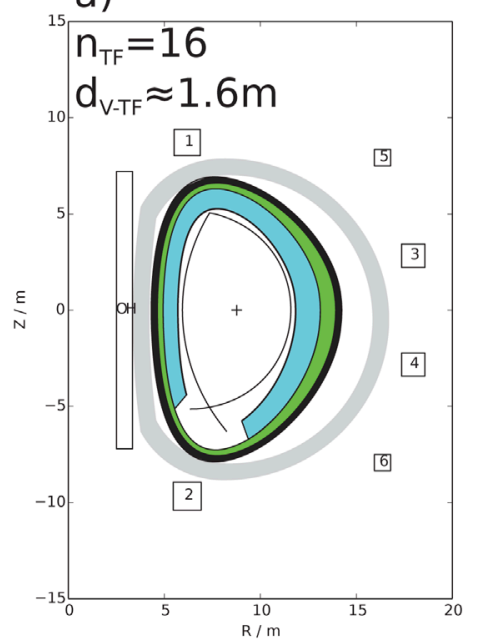

b)

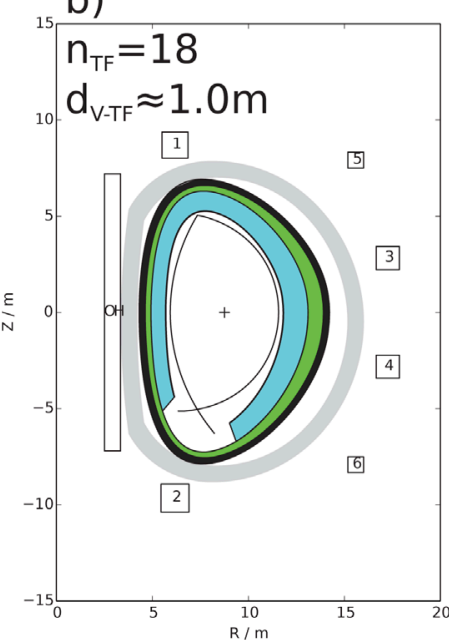

c)

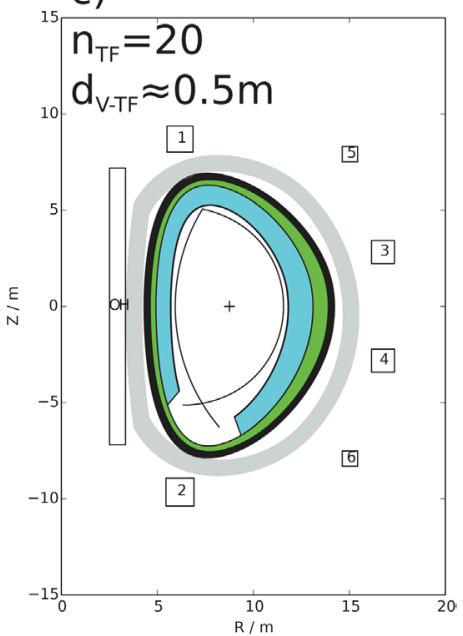

Figure 1. Effect of changing $n_{\mathrm{TF}}$ on $d_{V-\mathrm{TF}}$ at constant aspect ratio $A=3.1$ from a system code calculation. The grey shaded area represents the TF coil, the PF coils are labeled 1 to 6 , the CS coil is labelled OH. The black area represents the vacuum vessel, the green the shield ${ }^{9}$ and the blue area the blanket. The black solid lines mark the separatrix and the cross the plasma center. Ferritic inserts are not represented. The maximum allowed ripple in the confined region is $0.6 \%$.

of the device. The DEMO physics basis related to the triangularity has significant gaps. For instance, the effects of high/ low triangularity for more DEMO relevant conditions need to be studied experimentally and the efficiency of ELM mitigation methods need to be studied for DEMO as a function of triangularity. Considering this situation, the value that ITER uses in the $Q=10$ scenario, $\delta_{95}=0.33$, has been chosen for DEMO.

In TCV L-mode plasmas it has been seen that the midradius electron heat diffusivity is significantly decreasing with decreasing triangularity and, for similar plasma conditions, only half of the heating power is required at a triangularity of -0.4 compared with +0.4 to obtain the same temperature profile [13]. Based on this, it is proposed to consider negative triangularity for DEMO, as the power exhaust challenge would also be relaxed. In this pre-conceptual design phase for DEMO this option should also be investigated. Next to integration aspects, a key question will be the balance of possible positive aspects for the core confinement and possible negative aspects for the pedestal.

3.2.4. Number of TF coils. Increasing the magnetic inhomogeneity, which to first order can be quantified by the toroidal field ripple $\delta_{\mathrm{TF}}=(\max (B)-\min (B)) /(\max (B)+\min (B))$, has detrimental effects on the plasma such as a reduction of the pedestal pressure including the related reduction of confinement, a reduction of plasma rotation and an increase of fast particle losses. Initial investigations-disregarding losses due to fluctuations and waves in the plasma-suggest that the fast particle effects can be tolerable, especially if the design includes ferritic inserts between the shells of the vessel [14]. The ripple effect on the pedestal and rotation have been studied in TF ripple experiments in JET [15]. The resulting recommendation for ITER is to have TF ripple

${ }^{9}$ In all recent European DEMO designs (incl. EU DEMO1 2015) blanket and shield are integrated into one single component.

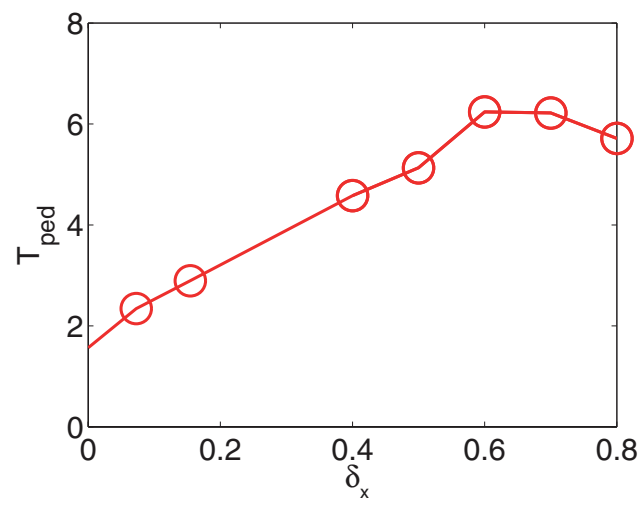

Figure 2. Pedestal top temperature $T_{\text {ped }}$ as a function of triangularity $\delta_{x}$ at the plasma edge based on calculations with the EPED1 model [21]: the parameters $n_{\text {ped }}, \beta, I_{\mathrm{P}}, R$ and $a$ are constant.

values inside the confined region of less than $0.5 \%$. For the development of EU DEMO1 2015 a value of $0.3 \%$ has been used as a guideline.

When developing DEMO designs there are several possibilities to decrease $\delta_{\mathrm{TF}}$ : (1) increasing the number of toroidal field coils $n_{\mathrm{TF}}$, (2) increasing the radial gap $d_{V-\mathrm{TF}}$ between the vessel and the outer leg of the TF coil, (3) introducing ferromagnetic materials between the two shells of the vacuum vessel on the outboard side. In the design EU DEMO1 2015 it is assumed that the maximum possible amount of ferromagnetic inserts between the vessel shells are installed, in order to reduce the TF ripple. Figure 1 shows the effect of changing $n_{\mathrm{TF}}$ on $d_{V-\mathrm{TF}}$ at constant $\delta_{\mathrm{TF}}$ and constant aspect ratio from a system code calculation. It has to be noted that in the system code the effect of ferromagnetic inserts is not featured. As it has been observed that the effect of the ferritic inserts is equivalent up to a reduction of about $0.3 \%$, the limit of $n_{\mathrm{TF}}$ in the system code has been set to $0.6 \%$. The impact of $n_{\mathrm{TF}}$ and $A$ on the remote maintenance speed and feasibility is discussed in section 3.2.2. Considering the choice $A=3.1$, the number of TF coils has been fixed to $n_{\mathrm{TF}}=18$ for EU DEMO1 2015 . 
3.2.5. Edge safety factor. Increasing the edge safety factor $q_{95}$ and keeping the other design parameters constant leads to a decrease in $I_{\mathrm{P}}$, which for DEMO1 would lead to an increase in the pulse duration. On the other hand, a decrease in $I_{\mathrm{P}}$ leads to a decrease in confinement and hence system code solutions often sit at the lowest permitted level in $q_{95}$.

At low values of $q_{95}$ the plasma is more prone to instabilities, although a quantification of this effect for DEMO conditions (i.e. a device to be operated in one single discharge scenario) is not available. A hard limit is reached, if $q_{95}$ falls below 2, when the $m=2, n=1$ external kink mode is destabilized and eventually leads to a disruption [16]. An investigation of JET discharges [17] shows that the disruptivity clearly increases for $q_{95}<2.5$ and that it is constant for $q_{95}>3.5$. Considering these aspects, in the system code a conservative limit of $q_{95} \geqslant 3.0$ is used.

\subsection{Physics parameters}

3.3.1. Pedestal top parameters. In the PROCESS version used for the development of EU DEMO1 2015 the representation of the pedestal shape is primarily used for the calculation of the radial radiation distribution. The pedestal top density $n_{\text {ped }}$ should be maximized in favor of maximizing the density across the profile and consequently the fusion power. Although there is recent progress in the understanding of edge density limits [18] a reliable extrapolation to DEMO is still not possible. We use the assumption that $n_{\text {ped }}$ is $85 \%$ of the Greenwald density limit [19]. The pedestal top temperature is calculated from linear stability calculations of the pedestal top pressure in combination with $n_{\text {ped }}$. For the design EU DEMO1 2015 a pedestal top temperature of about $5.5 \mathrm{keV}$ has been calculated with MISHKA [20] assuming a pedestal width of $\Delta \psi_{\text {ped }}=7 \%$. Calculations using the EPED1 model [21] arrive at a similar value with $\Delta \psi_{\text {ped }}=4 \%$ of the total poloidal flux. Positive dependency of the predicted pedestal temperature is found for triangularity (figure 2 ) and $\beta$. Increasing density increases the predicted pedestal top pressure, but decreases pedestal top temperature. Varying the plasma impurity content has a negligible effect.

3.3.2. Impurity related parameters. In order to achieve the required level of radiation power from inside and outside the separatrix, DEMO has to have a high level of impurity seeding. The optimum impurity species or impurity mix has been investigated with relatively basic tools [12]. Due to the extensive uncertainties in the assumptions for these calculations this has to be continued with more detailed simulations. This mix needs to be tailored in such a way that (1) the power to both divertor targets is below the tolerable threshold, (2) the loss power across the separatrix is higher than $P_{\mathrm{LH}}$ and (3) the fusion power is maximised. Based on some preliminary results, for EU DEMO1 $2015 \mathrm{Xe}$ has been used as seed

${ }^{10}$ The results from [12] suggest that the radiation capability of Xe in the $\mathrm{SOL} /$ divertor is insufficient and hence a significant amount of Ar or a lower $Z$ impurity should be added. impurity ${ }^{10}$. Changing to $\mathrm{Ar}(\mathrm{Kr})$ reduces the $P_{\mathrm{el}, \text { net }}$ by $23 \%$ $(10 \%)$ and the pulse duration by $6 \%(6 \%)$.

The recent design assumptions for DEMO imply a first wall with $\mathrm{W}$ armour. Therefore, it is expected that a significant amount of $\mathrm{W}$ is sputtered from the first wall and transported to the plasma. However, predicting the concentration of $\mathrm{W}$ in the plasma is not straightforward as there are open questions in various processes including sputtering at the wall, transport in the SOL and in the pedestal region. For instance, a highly relevant and open question is, in which ELM regime or with which ELM mitigation method DEMO will be operated. A default value of $c_{W}=5 \times 10^{-5}$ is used in EU DEMO1 2015 .

In a COREDIV [22] simulation of EU DEMO1 2015 with Ar as seed impurity for values of $P_{\text {sep }}$ just above the L-H threshold power a W concentration of $10^{-4}$ has been found. In PROCESS for EU DEMO1 2015 a change of the $\mathrm{W}$ concentration from $5 \times 10^{-5}$ to $10^{-4}$ leads to a reduction of the $\mathrm{Xe}$ seed impurity concentration from $4 \times 10^{-4}$ to $2 \times 10^{-4}$, $+5 \%$ net electric power and $+16 \%$ pulse duration due to decreased overall plasma dilution. However, it has to be noted that impurity control becomes more challenging when going in this direction.

Also the concentration of He in DEMO is very difficult to estimate: the production rate is quite predictable, but the transport to the plasma edge and the processes in the SOL are partly not understood and partly depend on some open aspects (e.g. ELM behavior). Also the efficiency of the pumping in DEMO can have significant impact on the He confinement.

The ITER Physics Basis [23] reports a lower limit for the ratio of He confinement time accounting for wall recycling and energy confinement time $\tau_{\mathrm{He}}^{*} / \tau_{E}$ of 6 . A reduction of the divertor neutral gas influx [24] or reduced ELM behavior leads to an increase of this value up to an order of magnitude. The He concentration in EU DEMO1 2015 of $c_{\mathrm{He}}=10 \%$ corresponds to $\tau_{\mathrm{He}}^{*} / \tau_{E}=6.5$. Increasing $\tau_{\mathrm{He}}^{*} / \tau_{E}$ to 12.6 would correspond to $c_{\mathrm{He}}=16 \%$ and a reduction of $P_{\mathrm{el}, \text { net }}$ by $52 \%$ and an increase of $\tau_{\text {pulse }}$ by $29 \%$ ( $c_{\mathrm{Xe}}$ is lower and therefore the ohmic power is lower).

3.3.3. H-mode access and confinement. The target regime of operation of EU DEMO1 2015 is the H-mode. We assume that this necessitates that the power crossing a flux surface close to and inside of the separatrix needs to exceed the L-H-threshold power $P_{\mathrm{LH}}$. For the prediction of $P_{\mathrm{LH}}$ the scaling from Martin [8] is employed. It has been observed that in machines with $\mathrm{W}$ walls, as it is planned for DEMO, $P_{\mathrm{LH}}$ is reduced by $20-30 \%$ [25]. On the other side it is desirable that $P_{\text {sep }}$ exceeds $P_{\text {LH }}$ by a certain ratio to ensure sufficient controllability and confinement quality [26]. Accounting for these aspects for the development of EU DEMO1 2015 the limit $f_{\mathrm{LH}}=P_{\text {sep }} / P_{\mathrm{LH}, \mathrm{scal}}=1$ is used-however, based on upcoming control investigations and on experiments with DEMO relevant impurity types and concentrations it might be necessary to increase $f_{\mathrm{LH}}$.

An investigation of the heating requirements for the ramp-up for DEMO1 has been performed with METIS [27, 28]. Using again the scaling from Martin [8], which is the LH-threshold scaling leading to the highest power requirements, 150MW of heating power have been found to be sufficient. 


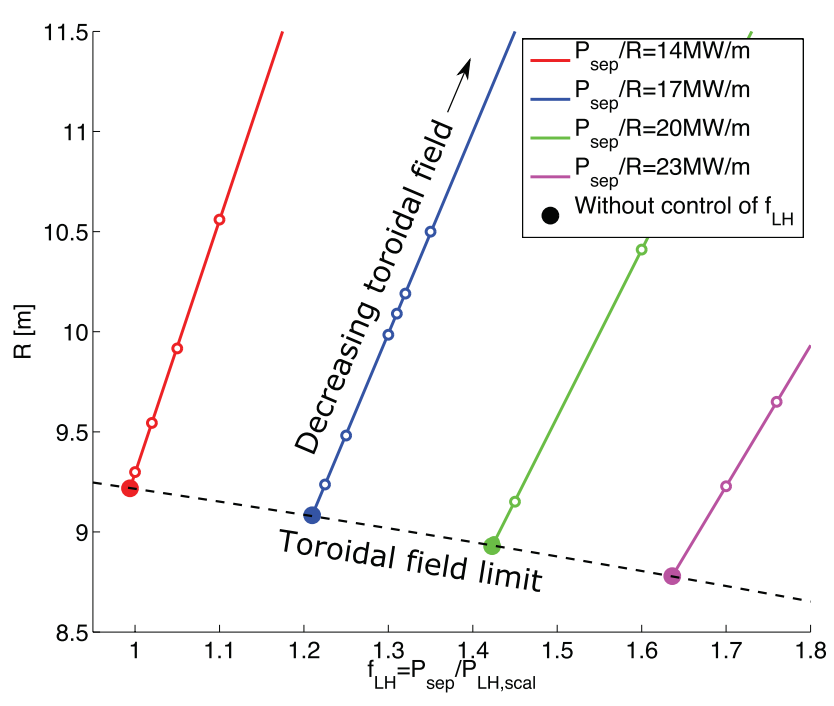

Figure 3. Dependence of the major radius on $f_{\mathrm{LH}}$ and $P_{\mathrm{sep}} / R$ from PROCESS calculations: $P_{\mathrm{el}, \text { net }}=500 \mathrm{MW}$ and $\tau_{\text {pulse }}=2 \mathrm{~h}$, while the major radius was minimized.

We note that the interaction of the divertor protection limit and the H-mode access limit may significantly drive the size of the device: assuming that the divertor challenge quantifier $P_{\text {sep }} / R$ (section 3.3.4) is fixed and applying the Martin and Greenwald scalings leads to $f_{\mathrm{LH}} \propto B^{-1.5} R^{-0.1}$. Consequently, increasing $f_{\mathrm{LH}}$ while limiting $P_{\mathrm{sep}} / R$ can only be accomplished by reducing the magnetic field, which leads to an increase in the required machine size in order to keep the same fusion power.

Figure 3 shows the result of a PROCESS study that also comes to the conclusion that the device size is very sensitive on the combination of $P_{\text {sep }} / R$ and $f_{\mathrm{LH}}$. Decreasing for instance $P_{\mathrm{sep}} / R$ from $17 \mathrm{MW} \mathrm{m}^{-1}$ to $14 \mathrm{MW} \mathrm{m}^{-1}$ at $f_{\mathrm{LH}} \approx 1.2$ results in an increase of the major radius of $3 \mathrm{~m}$. In addition the consequence of the L-H-threshold power uncertainty becomes clear: if the real H-mode threshold were higher than the scaled one, this would result in a corresponding increase in $f_{\mathrm{LH}}$. For instance an increase of the H-mode threshold by $100 \%$ (upper end of the $95 \%$ confidence interval for ITER [8]) would correspond to doubling $f_{\mathrm{LH}}$ and correspondingly roughly doubling the major radius of the device.

The H-mode confinement factor represents aspects of the discharge, which influence the confinement and which are not captured by the applied H98 $(y, 2)$ confinement scaling. As DEMO is designed to have a high level of radiated power inside the confined region in contrast to the experiments entering the confinement scaling it is important to carry out a correction in following equations

$$
\begin{gathered}
\tau_{E, I P B 98(y, 2)=} f\left(I_{P}, B_{T}, n, R, A, \kappa, M\right) P_{\mathrm{L}, \text { corr }}^{-0.69} \\
\tau_{E}=W / P_{\mathrm{L}, \mathrm{corr}},
\end{gathered}
$$

where $M$ is the ion mass number. The radiation corrected power loss is defined as $P_{\mathrm{L}, \text { corr }}=P_{\alpha}+P_{\text {aux }}-P_{\text {rad,core, }}$, where $P_{\text {rad,core }}$ are the assumed instantaneous losses to the heating power that do not enter the confinement scaling. Studying detailed ASTRA/TGLF [29-31] simulations of EU DEMO1 2015 [32] it is found that the most appropriate definition of $P_{\text {rad,core }}$ is $60 \%$ of the radiation integrated from the plasma centre up to a normalised minor radius $\rho_{\text {core }}=0.75$ [33]. However, the result of a preliminary analysis suggested subtracting all radiation within $\rho_{\text {core }}=0.6$, which is still an equally good model given the other uncertainties in this ad hoc correction. This latter approach has been used for EU DEMO1 2015 and EU DEMO1 2015. The difference between these two definitions of $P_{\text {rad,core }}$ has been found to have an insignificant effect on the performance parameters in PROCESS.

In the recent version of PROCESS (i.e. without the recently developed core transport model) the confinement factor $\mathrm{H}$ has a strong impact on the performance. In $\mathrm{N}$ seeded $\mathrm{H}$-mode discharges in ASDEX Upgrade with a core radiation fraction around $35 \%$ at $\beta_{N \text {,tot }}=2.6 \%$ a non-radiation corrected $\mathrm{H}$ around 1.2 has been observed [34]. $\mathrm{N}$ seeding is unfavorable in DEMO due to the extensive plasma dilution that is connected to it. Hence, to be conservative for EU DEMO1 2015 a non-radiation corrected value $\mathrm{H}$ of 1.0 corresponding to a radiation corrected value of 1.1 is assumed.

On the one hand $\mathrm{H}$ could be increased by operation in advanced or hybrid scenarios, which are now operated routinely. On the other hand, it is possible that any method to sufficiently [7] mitigate ELMs in DEMO implies a reduction of the pedestal top pressure [35] and hence a reduction of confinement.

3.3.4. Divertor protection parameter. It is expected that the divertor power exhaust problem in DEMO is significantly more challenging than in ITER [36, 37]. For any divertor configuration it will be essential to optimise by seeding impurities the fraction of the loss power that is radiated from the main chamber and the SOL and divertor region.

There is some doubt as to the predictive capability for the performance of a standard detached divertor in DEMO in H-mode operation as it is integrated in EU DEMO1 2015. Therefore, in the system codes a limit for the ratio $P_{\mathrm{sep}} / R$ is used. For attached divertor conditions it has been found that $\lambda_{q}$ and $S$ do not scale with $R$ [38-40]. Assuming that the same also holds for detached divertor conditions, $P_{\mathrm{sep}} / R$ is proposed as a measure for the divertor challenge $[41]^{11}$. While $10 \mathrm{MW} \mathrm{m}^{-1}$ has been successfully demonstrated in ASDEX Upgrade with a time averaged peak heat flux at the outer divertor target of about $5 \mathrm{MW} \mathrm{m}^{-2}$ [42], ITER is expected to operate at $15 \mathrm{MW}$ $\mathrm{m}^{-1}$ [36]. Based on the material limit for ITER-like divertors of $10 \mathrm{MW} \mathrm{m} \mathrm{m}^{-2}$ and the higher neutron load in the DEMO divertor, which might in practice reduce the material limits with respect to ITER, in the system code studies a limit of 17 MW $\mathrm{m}^{-1}$ is assumed for EU DEMO1 2015.

In order to stay within the $P_{\text {sep }} / R$ limit, PROCESS increases the impurity concentration $f_{\mathrm{imp}}=n_{\mathrm{imp}} / n_{e}$ until the power conducted or convected across the separatrix is equal to the $f_{\mathrm{LH}} \times P_{\mathrm{LH}, \text { scal }}$ or $P_{\text {sep }} / R$ falls below the prescribed threshold. Due to the associated fuel dilution and corresponding

\footnotetext{
${ }^{11} P_{\mathrm{sep}} B /\left(q_{95} R\right)$ is an interesting alternative for such a quantity that captures
} the main dependences of $\lambda_{q}\left(\propto q_{95} / B\right.$ [38]). 
reduction in fusion power, higher values of $P_{\text {sep }} / R$ lead to larger devices (figure 3).

\subsection{Technical parameters}

3.4.1. Heating and current drive. Heating and current drive (HCD) systems have to fulfil a comprehensive set of functions in DEMO. The requirements for the HCD systems change over the phases of the discharge. A preliminary list of these functions for DEMO1 is:

- breakdown assistance

- heating to L-H-transition and target $P_{\text {fus }}$

- burn and power exhaust control

- NTM control

- sawtooth control

- impurity accumulation control

- event handling. ${ }^{12}$

By far not all of these functions are represented in system codes. Also, the HCD mix for DEMO is not yet defined ${ }^{13}$. Therefore, as an umbrella an average power coupled to the plasma for both heating and current drive of $50 \mathrm{MW}$ during the plasma flat top phase is assumed. This value is certainly lower than the peak amount of coupled power, which has to be accounted for when dimensioning the installed power. Considering the relatively low expected power $(\leqslant 15 \mathrm{MW})$ requirement for NTM control [12], there is considerable power $(\geqslant 35 \mathrm{MW})$ available for burn and power exhaust control and sawtooth control. Further control investigations need to clarify whether this is sufficient.

For EU DEMO1 2015 HCD by neutral beam injection has been assumed. A wall plug efficiency of $\eta_{\mathrm{WP}}=0.4$ has been chosen based on quite diverging initial estimates $[43,44]$. Considering the wall plug efficiencies proposed in [45] this value should be reduced to 0.3 , which reduces $P_{\mathrm{el}, \text { net }}$ by $8 \%$. A normalised current drive efficiency $\gamma_{\mathrm{CD}}=0.27 \times 10^{20} \mathrm{~A} /\left(\mathrm{W} \mathrm{m}^{2}\right)$ in line with recent simulations [46] is calculated in PROCESS. These parameters are defined assuming a neutral beam voltage of 1.0 MV.

The total plasma current of this design splits into $55 \%$ inductive current, $35 \%$ bootstrap current and only $10 \%$ externally driven current. Hence, the pulse duration is not very sensitive to the value of $\gamma_{\mathrm{CD}}$, whereas the value of $\eta_{\mathrm{WP}}$ has a big impact on the recirculating electrical power of DEMO.

\subsubsection{Blanket, balance of plant and recirculated power.} System codes mainly feature static power requirements of plant systems. More information on the time-dependent power requirements for pulsed fusion reactors can be found in [47]. During the start-up phase DEMO might even require net external power supply.

$\mathrm{He}$ at 80 bar and $\mathrm{H}_{2} \mathrm{O}$ under pressurized water reactor conditions, both with an inlet temperature of $\approx 300{ }^{\circ} \mathrm{C}$, are the

\footnotetext{
${ }^{12}$ Definition of the detailed functions in the area of event handling need to be developed.

${ }^{13}$ A systematic evaluation of the most advantageous HCD mix to fulfill all required functions is a long-term activity that has been initiated
}

options for the main (i.e. blanket) coolant of DEMO. In the secondary loop a Rankin cycle is implemented. He cooling has a gross thermal efficiency $P_{\mathrm{el}, \text { gross }} / P_{\mathrm{th}, \text { gross }}$ accounting also for energy storage requirements of $37 \%\left(\mathrm{H}_{2} \mathrm{O}\right.$ cooling: $\left.32 \%\right)$ but also a higher required pumping power of $155 \mathrm{MW}\left(\mathrm{H}_{2} \mathrm{O}: 20\right.$ MW) [48]. In the definition of EU DEMO1 $2015 \mathrm{He}$ is assumed as blanket coolant. Changing the thermal efficiency and the pumping requirements to water as a main coolant reduces the net electric power by $8 \%$.

The thickness of the inner (outer) breeding blanket $t_{\mathrm{blkt}, \mathrm{ib}}$ $\left(t_{\mathrm{blkt}, \mathrm{ob}}\right)$ is an important parameter for the radial build of the device. In the definition of these dimensions the impact on the Tritium breeding ratio and the required space for the blanket manifold feeding the first wall and the breeding units need to be accounted for. Based on initial investigations values for these thicknesses to be used in system code studies have been found to be independent of the type of the blanket design option: $t_{\mathrm{blkt}, \mathrm{ib}}=0.78 \mathrm{~m}$ and $t_{\mathrm{blkt}, \mathrm{ob}}=1.30 \mathrm{~m} \mathrm{[49]}$.

Of $913 \mathrm{MW}$ gross electric power $45 \%$ are recirculated to following systems: $30 \%$ HCD systems, $38 \%$ He coolant pumping, $4 \%$ Tritium systems, $7 \%$ cryogenic systems, $14 \%$ facilities heating and $7 \%$ remaining systems.

3.4.3. Magnet systems. At present, several different concepts exist for the TF and central solenoid (CS) coil winding packs in DEMO. $\mathrm{Nb}_{3} \mathrm{Sn}$ is currently the most developed superconductor in terms of achieving high magnetic fields in fusion coils and is the material of choice for these coils. Some winding pack concepts for the TF and CS coils are layered, meaning that the conductors can be graded along the thickness, enabling cheaper superconductor materials (NbTi) to be used in low field areas. PROCESS currently assumes a pancake-winding approach, as used in ITER. The poloidal field coils are presently assumed to be made exclusively of $\mathrm{NbTi}$, due to the lower field requirements.

\section{Impact of uncertainties}

Table 3 shows the impact of a modification of $\pm 10 \%$ of a number of input parameters on the net electric power and pulse duration. Certainly the uncertainty on each parameter is not the same and in [50] a proposal for the probability distribution of system code input parameters is presented.

The strongest sensitivities are found for $A, \kappa_{95}, H$ and the Greenwald density fraction. The various facets of the aspect ratio selection have been discussed in section 3.2.2. The importance of the confinement factor is evident and various strategies to reduce the uncertainty are discussed in [12]. Also the impact of the Greenwald density fraction can be easily understood, however the uncertainty in predicting this value is quite large.

To explain the strong sensitivity to the elongation the dependence of $P_{\text {fus }}$ on $\kappa_{95}\left(\Delta \kappa_{95}=10 \%\right.$ corresponds to $\left.\Delta P_{\text {fus }}=75 \%\right)$ is analysed:

Assuming fixed $R, B_{T, 0}, a, q_{95}$ and $P_{\text {loss }}$ (divertor protection) and the IPB98 $(y, 2)$ scaling for the energy confinement time and operation at a fixed Greenwald fraction leads to 
Table 3. Relative impact of a modification of $\pm 10 \%$ of a number of input parameters on the net electric power and pulse duration: al PROCESS runs have been carried out with fixed major radius and optimising the ratio fusion of power and injection power.

\begin{tabular}{lrrrr}
\hline & \multicolumn{2}{c}{$P_{\text {el,net }}$} & & \multicolumn{2}{c}{$\tau_{\text {pulse }}$} \\
\cline { 2 - 5 } & $-10 \%$ & $+10 \%$ & $-10 \%$ & $+10 \%$ \\
\hline$A$ & $48 \%$ & $-49 \%$ & $-42 \%$ & $60 \%$ \\
$\kappa_{95}$ & $-75 \%$ & $125 \%$ & $28 \%$ & $-7 \%$ \\
$\delta_{95}$ & $-12 \%$ & $13 \%$ & $3 \%$ & $-3 \%$ \\
$c_{W}$ & $0 \%$ & $0 \%$ & $1 \%$ & $17 \%$ \\
$c_{\text {He }}$ & $10 \%$ & $-9 \%$ & $4 \%$ & $29 \%$ \\
\hline$H$ & $-35 \%$ & $27 \%$ & $-8 \%$ & $15 \%$ \\
$P_{\text {aux }}$ & $1 \%$ & $-1 \%$ & $-1 \%$ & $1 \%$ \\
$P_{\text {sep }} / R$ & $-3 \%$ & $3 \%$ & $-5 \%$ & $5 \%$ \\
$\eta_{\text {WP }}$ & $-3 \%$ & $2 \%$ & $0 \%$ & $0 \%$ \\
$P_{\text {Tritium }}$ & $0 \%$ & $0 \%$ & $0 \%$ & $0 \%$ \\
$t_{\text {blkt,ib }}$ & $9 \%$ & $-16 \%$ & $8 \%$ & $-5 \%$ \\
$t_{\text {blkt,ob }}$ & $0 \%$ & $0 \%$ & $0 \%$ & $0 \%$ \\
$\left\langle n_{\text {li }}\right\rangle / n_{\mathrm{GW}}$ & $-28 \%$ & $30 \%$ & $5 \%$ & $-2 \%$ \\
$T_{0} /\left\langle T_{\mathrm{e}}\right\rangle$ & $-2 \%$ & $1 \%$ & $-1 \%$ & $1 \%$ \\
\hline & & & & \\
\hline
\end{tabular}

Note: The variations of $A, t_{\mathrm{blkt,ib}}$ and $t_{\mathrm{blkt}, \mathrm{ob}}$ have been done in such a way that the only flexible elements of the radial build are machine bore (i.e. inner radius of CS coil) and minor plasma radius.

$$
\begin{aligned}
& W / P_{\text {loss }} \propto I_{P}^{0.9} \kappa^{0.8} n^{0.4} P_{\text {loss }}^{-0.7} \text { with } \\
& n \propto I_{P} / a^{2} \propto I_{P} \text { and } \\
& I_{P} \propto 1+\kappa_{95}^{2}\left(1+2 \delta_{95}-1.2 \delta_{95}^{2}\right) \approx 1+1.5 \kappa_{95}^{2} \text { leading to } \\
& P_{\text {fus }} \propto n^{2} T V \propto n W \propto n I_{P}^{0.9} \kappa^{0.8} n^{0.4} P_{\text {loss }}^{0.3} \propto I_{P} I_{P}^{0.9} \kappa^{0.8} I_{P}^{0.4} \\
& \quad \propto\left(1+1.5 \kappa_{95}^{2}\right)^{2.3} \kappa^{0.8} \propto \kappa^{5.4} .
\end{aligned}
$$

An increase of $P_{\text {fus }}$ by $75 \%$ corresponds to a $\kappa$-exponent of 5.5. Due to this high sensitivity an extensive program to optimize the maximum allowable elongation in terms of vertical stability has been initiated [12].

In addition to these single-parameter sensitivities it is interesting to study multi-parameter effects. On the one hand there might be off-diagonal effects, in which several parameter dependencies increase each other. On the other hand, it is important to understand the total uncertainty of the performance parameters of a certain design point. Some of these aspects are addressed in [50].

\section{Summary}

The discussion about the fusion device succeeding ITER is gaining more and more importance. In Europe a significant effort is dedicated to the development of a conceptual design for DEMO. The consistency of the assumptions entering this development is of key importance and often extremely optimistic parameters are used. In order to provide transparency, in this paper the key input parameters for the design EU DEMO1 2015 and their justifications are discussed. It is obvious that the uncertainties in these parameters need to be reduced by the development of the relevant parts of the DEMO Physics Basis and of engineering models for DEMO.
All input parameters for EUDEMO1 2015 have been chosen conservatively, in line with the requirement that it needs to be possible to develop a consistent engineering design for this machine within the next 20 years. However, it has to be mentioned that there are a number of non-negligible risks associated with the design EU DEMO1 2015, for which solutions or mitigation schemas need to be demonstrated and/ or implemented. These include the areas of divertor and first wall protection, edge localized modes and disruptions.

The impact of uncertainties on some input parameters has been investigated. The strongest effect on the performance parameters $P_{\mathrm{el} \text {,net }}$ and $\tau_{\text {pulse }}$ is caused by a $\pm 10 \%$ variation of aspect ration, elongation, confinement factor and Greenwald density fraction. Of these parameters the elongation is the one with the most extreme sensitivity $\left(\Delta \kappa_{95}=10 \%\right.$ corresponds to $\Delta P_{\mathrm{el} \text {,net }}=125 \%$ ). For this reason a verification of the vertical stability should be carried out for each DEMO design that is studied in detail.

The impact of these sensitivities on the performance uncertainty of EU DEMO1 2015 has not been studied. This requires that the uncertainty in all parameters with strong influence over the performance parameters needs to be better quantified in future studies.

Next to the impact of parameter choice on the performance of DEMO, the effects of uncertainties of scalings applied inside the system codes also need to be taken into account. In particular, the Martin scaling for the L-H-power threshold has an extensive uncertainty that results in a large machine performance uncertainty.

\section{Acknowledgments}

This work has been carried out within the framework of the EUROfusion Consortium and has received funding from the European Union's Horizon 2020 research and innovation programme under grant agreement number 633053. The views and opinions expressed herein do not necessarily reflect those of the European Commission.

\section{References}

[1] Kovari M., Kemp R., Lux H., Knight P., Morris J. and Ward D. 2014 Fusion Eng. Des. 89 3054-69

[2] Kovari M. et al 2016 Fusion Eng. Des. 104 9-20

[3] Reux C. et al 2015 Nucl. Fusion 55073011

[4] Romanelli F. et al 2012 Fusion electricity—a roadmap to the realisation of fusion energy (https://www.euro-fusion.org/ wpcms/wp-content/uploads/2013/01/JG12.356-web.pdf)

[5] Federici G. et al 2014 Fusion Eng. Des. 89 882-9

[6] Kemp R. et al 2013 https://idm.euro-fusion. org/?uid=2MDM37

[7] Wenninger R. et al 2015 42nd EPS Conf. on Controlled Fusion and Plasma Physics (Lisbon, 2015) (http://ocs. ciemat.es/EPS2015PAP/pdf/P4.110.pdf)

[8] Martin Y.R., Takizuka T. and The ITPA CDBM H-mode Threshold Database Working Group 2008 J. Phys.: Conf. Ser. 123012033

[9] Sauter O., Angioni C. and Lin-Liu Y.R. 1999 Phys. Plasmas 6 2834-9 
[10] Crofts O. et al 2015 Fusion Eng. Des. B 109-111 1392-8

[11] Wolff D. et al 2016 Private communication (https://idm.eurofusion.org/?uid=2MC4M8)

[12] Wenninger R. et al 2015 Nucl. Fusion 55063003

[13] Camenen Y. et al and The TCV Team 2007 Nucl. Fusion 47510

[14] Snickers A. et al 2015 Private communication (https://idm. euro-fusion.org/?uid=2MW7FC)

[15] Saibene G. et al 2008 Proc. 22nd Int. Conf. Fusion Energy (Geneva, 13-18 October 2008) (Vienna: IAEA) CD-ROM file EX/2-1 www-naweb.iaea.org/napc/physics/FEC/ FEC2008/html/index.htm

[16] Wesson J. 1978 Nucl. Fusion 1887

[17] de Vries P., Johnson M., Segui I. and JET Contributors 2009 Nucl. Fusion 49055011

[18] Bernert M. et al 2015 Plasma Phys. Control. Fusion 57014038

[19] Wenninger R. et al 2014 Nucl. Fusion 54114003

[20] Maget P. et al 2013 Nucl. Fusion 53093011

[21] Snyder P.B., Groebner R.J., Leonard A.W., Osborne T.H. and Wilson H.R. 2009 Phys. Plasmas 16056118

[22] Zagorski R., Ivanova-Stanik R. and Stankiewicz R. 2013 Nucl. Fusion $\mathbf{5 3} 073030$

[23] Ikeda K. 2007 Nucl. Fusion 47 E01

[24] Bosch H. 2000 Die Physik der Alpha-Teilchen in einem fusionsreaktor mit deuterium-tritium-plasmen habilitation

[25] Ryter F. et al 2013 Nucl. Fusion 53113003

[26] Loarte A. et al 2011 Phys. Plasmas 18056105

[27] Vincenzi P. et al 2016 SOFT Conf. (Prague, Czech Republic)

[28] Artaud J. et al 2010 Nucl. Fusion 50043001

[29] Pereverzev G.V. et al 1991 Lab Report Max-Planck-Institut fuer Plasmaphysik 5/42

[30] Fable E. et al and The ASDEX Upgrade Team 2013 Plasma Phys. Control. Fusion 55124028
[31] Staebler G.M., Kinsey J.E. and Waltz R.E. 2007 Phys. Plasmas 14055909 (1994-present)

[32] Fable E. et al 2017 Nucl. Fusion 57022015

[33] Lux H., Kemp R., Fable E. and Wenninger R. 2016 Plasma Phys. Control. Fusion $\mathbf{5 8} 075001$

[34] Kallenbach A. et al 2012 Proc. 24th Int. Conf. on Fusion Energy (San Diego, 8-13 October 2012) ITR/P1-28 www-naweb.iaea.org/napc/physics/FEC/FEC2012/index.htm

[35] Eich T. et al 2016 PSI Conf. (Rome)

[36] Zohm H. et al 2013 Nucl. Fusion 53073019

[37] Wischmeier M. et al 2015 J. Nucl. Mater. 463 22-9

[38] Eich T., Sieglin B., Scarabosio A., Fundamenski W., Goldston R.J. and Herrmann A. 2011 Phys. Rev. Lett. 107215001

[39] Eich T. et al 2013 Nucl. Fusion 53093031

[40] Sieglin B. et al 2013 Plasma Phys. Control. Fusion 55124039

[41] Kallenbach A. et al and The ASDEX Upgrade Team 2012 Nucl. Fusion 52122003

[42] Kallenbach A. et al 2015 Nucl. Fusion 55053026

[43] Maisonnier D. et al 2007 Nucl. Fusion 471524

[44] Pamela J. et al 2009 Fusion Eng. Des. 84 194-204 (Proc. of the 25th Symp. on Fusion Technology)

[45] Surrey E. et al 2011 Fusion Eng. Des. 86 793-6

[46] Zohm H. et al 2013 40th EPS Conf. on Controlled Fusion and Plasma Physics (Helsinki, Finland) (http://ocs.ciemat.es/ EPS2013PAP/pdf/O3.108.pdf)

[47] Morris J. et al 2016 Contribution to SOFT Conf. (Prague, Czech Republic)

[48] Latham H. and Clarkson P. 2013 Private communication (https://idm.euro-fusion.org/?uid=2LLNBX)

[49] Bachmann C. et al 2016 Fusion Eng. Des. in press

[50] Lux H. et al 2016 Contribution to SOFT Conf. (Prague, Czech Republic) 